\title{
New Developments in Long-Term Downhole Monitoring Arrays
}

\section{Introduction}

The long-term observation of active geological processes is a major research goal in an increasing number of scientific drilling projects. An extended monitoring phase within a potentially hostile environment (e.g., temperature, pressure, salinity) requires new long-lasting and robust instrumentation currently unavailable from either industry or academia. Extended exposure of instrument packages to extreme conditions will typically cause seals to weaken and fail, electronic parts to break under permanent load, and sensors to degrade or develop strong drift. In the framework of scientific exploration, there are currently several major research projects targeting fault zone drilling and in situ measure-

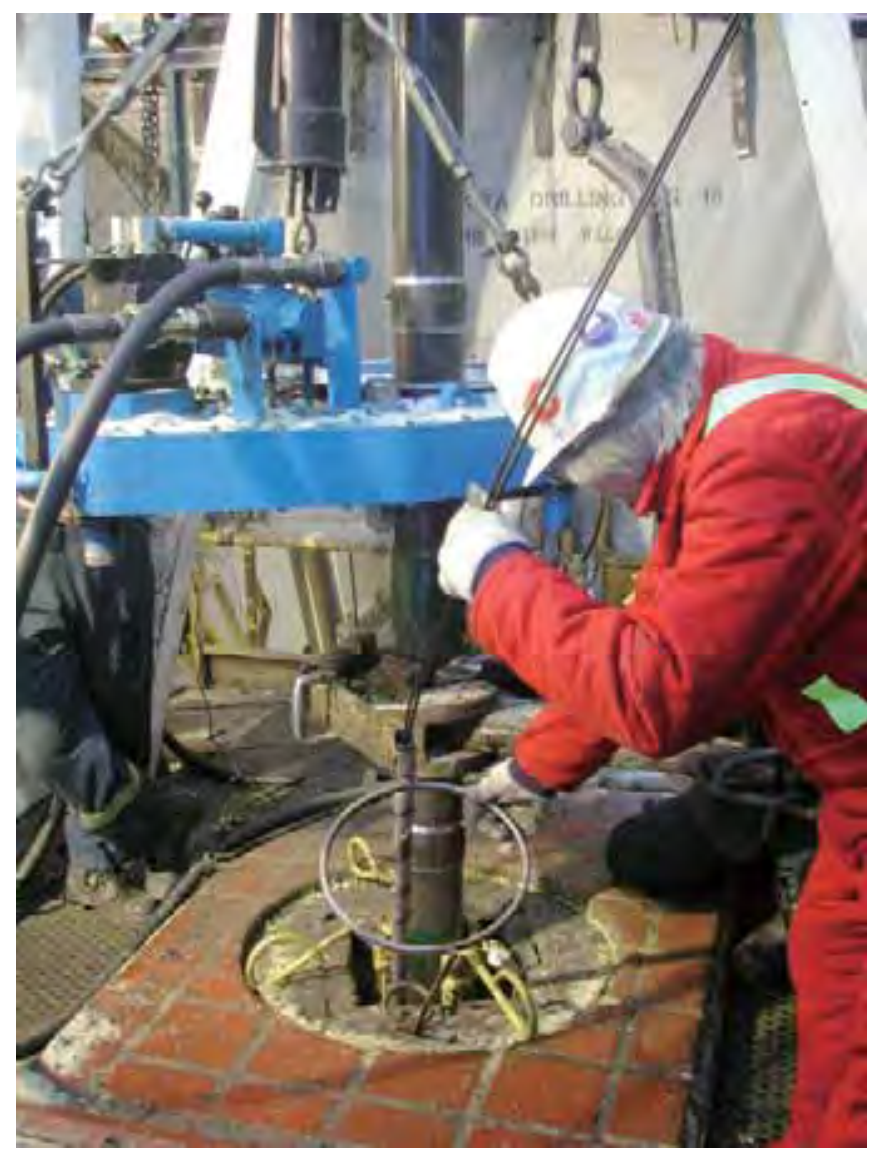

Figure 1. Distributed Temperature Profiling (DTS) fiber-optic cable installation for permanent temperature surveys behind the casing at Mallik Gas Hydrate drilling site in Canada. Fiber-optic cables are attached to the outside of the casing wall by special cable clamps to prevent cable damage while running into the hole.Special cable outlet connectors at the well head ensure safe data retrieval from the cemented borehole annulus to the surface. ments to monitor physical and chemical conditions before, during, and after seismic events. Planning has now begun for tool development, testing, and continuous long-term monitoring for the San Andreas Fault Zone Observatory at Depth, SAFOD (Parkfield, Calif., U.S.A.; See article on page 32.).

\section{State of Technology}

The prime technical objectives of a permanent monitoring array concern the reliability of components over time under borehole conditions, the repeatability of measurements and reproducibility of results, and the redundancy of the system in case of failure. In contrast to recent technological advances in drilling and logging techniques and imaging software tools, very little has been achieved in permanent borehole monitoring. In the hydrocarbon industry, even after the advent of horizontal drilling, long-term and reliable doublehole measurements were slow to emerge. Attempts to image geological structures by means of instrumented casings and smart wells never passed the experimental stage. Repeated 3 -D seismic surveys (4-D seismics) therefore remain the only and remote means to monitor subsurface dynamics, though the answers only provide indirect information at best.

Monitoring a deep scientific borehole traditionally has been restricted to measuring only a few parameters, such as pressure and temperature, possibly taking fluid samples, and recording seismicity via analog cable. The limited bandwidth and vulnerability of tools for those measurements can be overcome by using sensors made of fiber-optic cables (See on-site installation, Fig. 1.). Initially, distributed temperature measurements were made over the entire length of the borehole via one single fiber-optic cable. The next step was to measure pressure at discrete points with special grated fiber elements integrated in the cable. The latest fiber-optic application is the optical geophone based on the measurement of fiber strain acceleration.

Fiber-optic temperature surveys as part of long-tem monitoring have been obtained in several projects supported by the International Continental Scientific Drilling Program (ICDP) including the Hawaii Scientific Drilling Project and the Mallik Gas Hydrate Research Well (Fig. 1). In addition, strain measurements were recorded during the Gulf of Corinth and SAFOD projects. 
Table 1: A selection of commercially available sensor systems for the Type-1 permanent downhole monitoring installations.

\begin{tabular}{|l|l|c|c|c|c|c|}
\hline \multicolumn{1}{c}{ Type-1 } & \multicolumn{1}{c}{ Noisefloor } & dyn. Range & Sample rate & max. Temp & Telemetry \\
\hline 3c-Geophone $(4.5 \mathrm{~Hz}-2 \mathrm{kHz})$ & $10^{-5} \mathrm{~V} \cdot \mathrm{cm}^{-1} \cdot \mathrm{s}^{-1}$ & $100 \mathrm{~dB}$ & - & $180^{\circ} \mathrm{C}$ & analog, electr. \\
\hline 3c-Accelerometer $(1 \mathrm{~Hz}-800 \mathrm{~Hz})$ & $10^{-6} \mathrm{~g} \cdot \mathrm{Hz}^{-1}$ & $130 \mathrm{~dB}$ & $>0,25 \mathrm{~ms}$ & $175^{\circ} \mathrm{C}$ & optical \\
\hline Temperature Profiling & $10^{-2} \mathrm{~K}$ & $100 \mathrm{~dB}$ & - & $175^{\circ} \mathrm{C}$ & optical \\
\hline Pressure & $10^{-7} \mathrm{bar}$ & $130 \mathrm{~dB}$ & $>0,25 \mathrm{~ms}$ & $175^{\circ} \mathrm{C}$ & optical \\
\hline Strain Gauges & $10^{-6} \mathrm{VV} / \mathrm{V}$ & $120 \mathrm{~dB}$ & - & $175^{\circ} \mathrm{C}$ & electr., optical \\
\hline Tiltmeter & $10^{-4} \mathrm{rad}$ & $75 \mathrm{~dB}$ & $>2 \mathrm{~Hz}$ & $175^{\circ} \mathrm{C}$ & optical
\end{tabular}

Table 2: A selection of commercially available sensor systems for the Type-2 permanent downhole monitoring installations.

\begin{tabular}{|l|l|c|c|c|c|c|}
\hline \multicolumn{1}{c|}{ Type-2 } & \multicolumn{1}{c|}{ Noisefloor } & dyn. Range & Sample rate & max. Temp & Telemetry \\
\hline 3c-Geophone $(15 \mathrm{~Hz}-2 \mathrm{kHz})$ & $10^{-6} \mathrm{~V} \cdot \mathrm{cm}^{-1} \cdot \mathrm{s}^{-1}$ & $120 \mathrm{~dB}$ & $>0,25 \mathrm{~ms}$ & $150^{\circ} \mathrm{C}$ & optical \\
\hline 3c-Accelerometer $(\mathrm{DC}-1 \mathrm{kHz})$ & $10^{-6} \mathrm{~g} \cdot \mathrm{Hz}^{-1}$ & $120 \mathrm{~dB}$ & $>0,25 \mathrm{~ms}$ & $125^{\circ} \mathrm{C}$ & digtal, optical \\
\hline Temperature Pressure Gauge & $10^{-4}$ & $130 \mathrm{~dB}$ & $<10 \mathrm{~Hz}$ & $200^{\circ} \mathrm{C}$ & digital, electr. \\
\hline Strainmeter & $10^{-9} \mathrm{VV} / \mathrm{V}$ & $180 \mathrm{~dB}$ & $>1 \mathrm{~Hz}$ & $65^{\circ} \mathrm{C}$ & digital, electr. \\
\hline Tiltmeter & $10^{-8} \mathrm{rad}$ & $120 \mathrm{~dB}$ & $>1 \mathrm{~Hz}$ & $125^{\circ} \mathrm{C}$ & digital, electr.
\end{tabular}

\section{New Developments for Fault Zone Arrays}

High-precision permanent monitoring arrays and sensors are currently being developed to address the extremely harsh operating conditions and highest measurement requirements in fault-zone drilling projects. In situ stress and strain, as well as fluid activity in deforming zones, are major scientific goals of both ICDP-funded projects such as the SAFOD or the Taiwan Chelungpu Fault Drilling Project as well as in scientific ocean drilling. The typical downhole monitoring design requirements for such projects can be categorized into two modular end-member designs for different temporal and spatial scales. Type- 1 is a permanently and irretrievably installed cable consisting of passive, unpowered sensors attached to the outside wall of a lower casing and cemented in place. Such monitoring systems are typically based on fiber-optic cables but may also comprise analog electric and mechanical devices or hydraulic actuators with communication lines to the surface (Fig. 2). Currently, however, the excellent long-term stability of such systems will have to be compromised with limitations in measurement resolution, dynamic range, and sensor stability. Table 1 shows the sensors for Type- 1 designs that are commercially available today.

Type-2 are high-end measuring devices typically designed for several years of data acquisition and for recovery from the borehole for maintenance and sensor upgrade as well as recalibration. They are semi-permanently installed inside the last casing or inside the open hole section by cable, coiled tubing, or pipe conveyance from the surface. The array is actively powered from the surface at all times. Densely sampled data (4 $\mathrm{kHz}$ at 24-bit resolution) are transmitted digitally via copper or fiber-optic cable to the surface. Repeated repositioning of the array in the borehole is also possible for optimized resolution (Fig. 2). A selection of commercially available sensor systems for the Type-2 permanent downhole monitoring installations is compiled in Table 2.

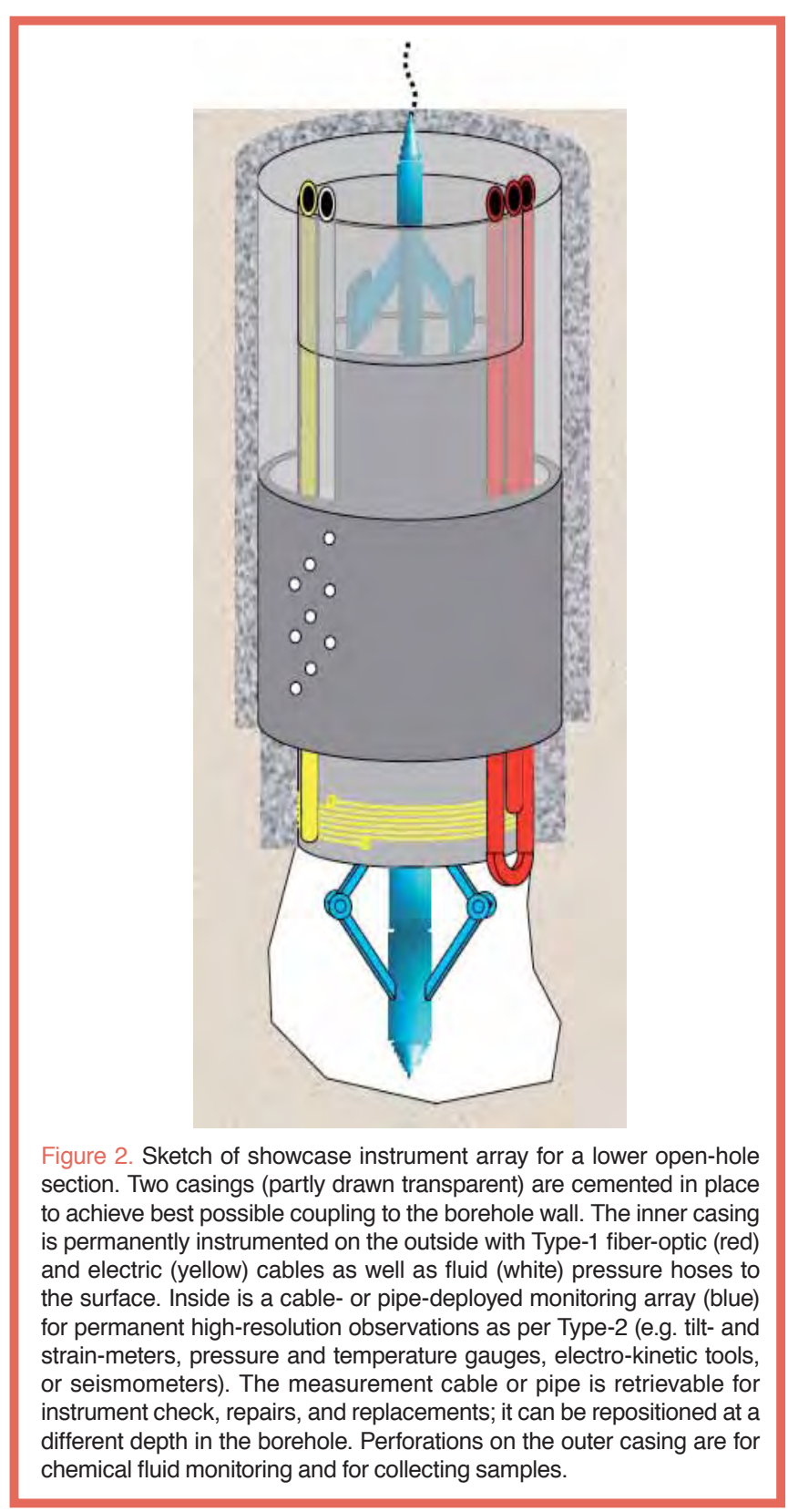




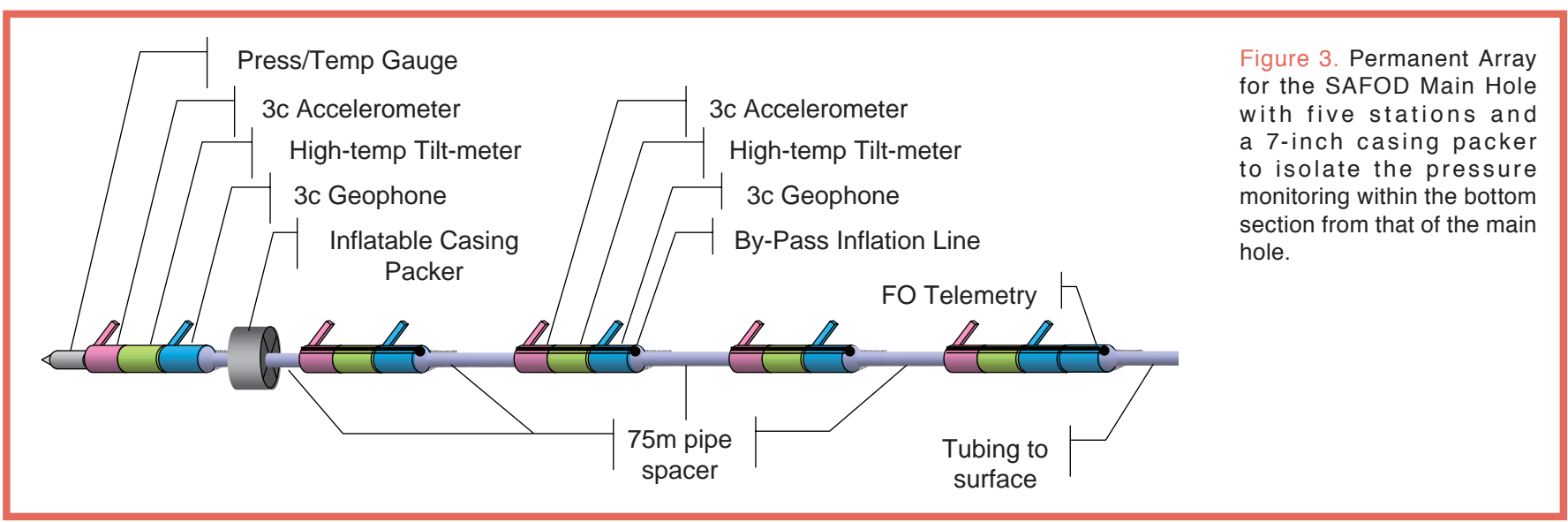

\section{A High Resolution Permanent Array for SAFOD Main Well}

The SAFOD comprises a pilot hole drilled in 2002 and a main borehole drilled in 2004-2005 (see p. 32). The latter was drilled vertically to almost $2 \mathrm{~km}$ and deviated to $58^{\circ}$ with classic oilfield directional drilling techniques. It penetrated the trace of the San Andreas Fault at about $3 \mathrm{~km}$ depth during the summer 2005 drilling campaign. The current monitoring installation in the main borehole comprises a fiber-optic cable for temperature and strain measurement (cemented outside the 9-5/8-inch casing) as well as a wireline deployed tool string with three-component geophones, accelerometers, and tilt-meters (inside the lower 7-inch casing portion). The latter tool is a prototype designed primarily to monitor magnitude 2 (M2) seismic events within a few

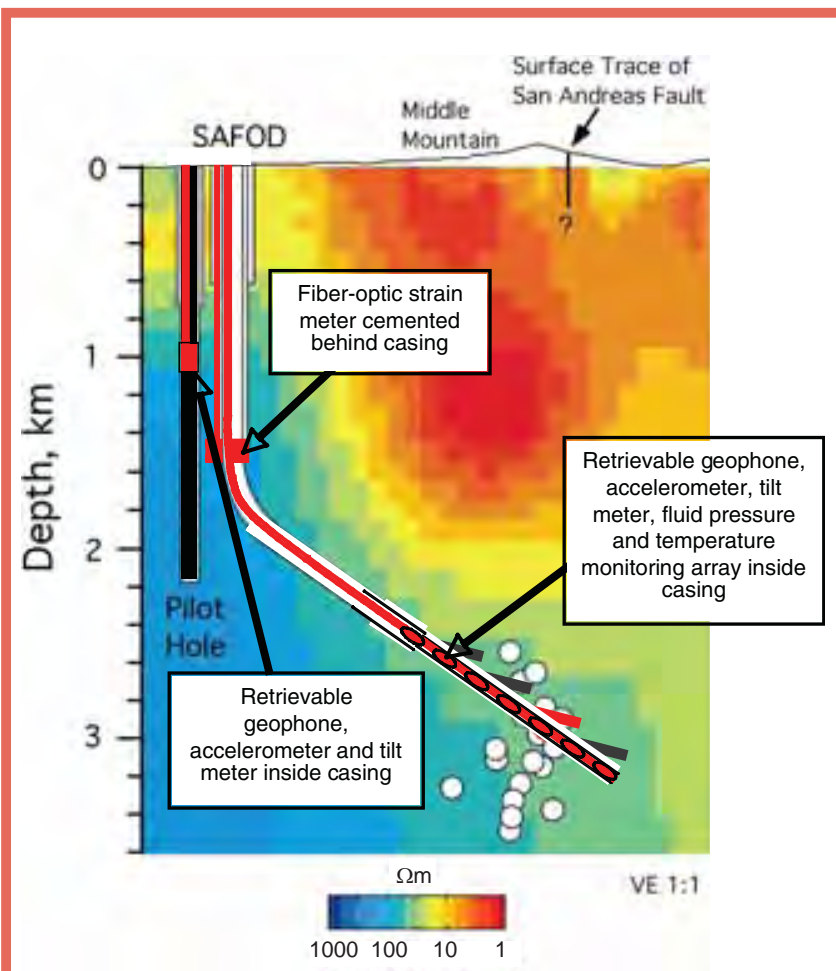

Figure 4. Scheme of SAFOD observatory. Seismic and tilt instrumentation is being deployed in the pilot hole. A fiber optics strain meter is installed behind the casing in the vertical section of the main hole. An array of seismometers, accelerometers and tiltmeters are being developed for deployment in the main hole. hundred meters of the borehole during a twelve-month period.

During the planned Phase-3 drilling from June to August 2007, a series of four continuously cored sidetrack holes will intersect the actively deforming traces of the San Andreas Fault near the existing main borehole. After completing the sidetrack coring program in 2007, a permanent Type-2 instrumentation array will be installed for a monitoring period of fifteen years (Fig. 4). It will consist of five stations, each equipped with a three-component geophone, a threecomponent accelerometer, and tilt-meters, spaced by 75 -m-long, electrically wired, rigid pipes. The bottom station of the array will also include pressure and temperature gauges. This part of the array will be positioned in one of the sidetrack holes and will be sealed off from the rest of the hole with a casing packer above the sidetrack point. To maintain roll-angle orientation, the entire array will be installed by pipe conveyance with cable and packer inflation lines leading to the surface. Borehole clamping arms will be pointing to the upper side of the hole to ensure optimum coupling to the borehole wall at each station. The development, construction, and testing of the retrievable monitoring array (as shown in Fig. 3) will be completed by August 2007, and the string will be installed in September 2007.

\section{Authors}

Bernhard Prevedel, Operational Support Group ICDP, GeoForschungsZentrum Potsdam, Telegrafenberg A34, D14473 Potsdam, Germany, e-mail: prevedel@gfz-potsdam.de Jochem Kück, Operational Support Group ICDP, GeoForschungsZentrum Potsdam, Telegrafenberg A34, D14473 Potsdam, Germany.

\section{Related Web Links}

http://mallik.icdp-online.org

http://www.earthscope..org

http://safod.icdp-online.org

\section{Figure Credit}

Fig.1: Jan Henninges, GFZ Potsdam. 